\title{
Chylothorax, new insights in treatment
}

\author{
Pavlos Papoulidis, Puwalani Vidanapathirana, Joel Dunning \\ Cardio-Thoracic Surgery Department James Cook University Hospital, Middlesbrough, UK \\ Correspondence to: Pavlos Papoulidis. Cardio-Thoracic Surgery Department James Cook University Hospital, Middlesbrough, UK. \\ Email: pavlos.papoulidis@nhs.net. \\ Provenance: This is an invited Editorial commissioned by the Section Editor Laura Chiara Guglielmetti (Cantonal Hospital Winterthur, Kantonsspital \\ Winterthur, Winterthur, Switzerland). \\ Comment on: Tang H, Bai Y, Shen W, et al. Anastomosis of the thoracic duct and the azygos vein for the treatment of recurrent chylothoraxes. Eur J \\ Cardiothorac Surg 2018;53:1093-4.
}

Submitted Aug 26, 2018. Accepted for publication Sep 11, 2018.

doi: $10.21037 /$ jtd.2018.09.94

View this article at: http://dx.doi.org/10.21037/jtd.2018.09.94

Approximately 2.4 liters of chyle is circulating through the lymphatic system every day. A rupture or damage of the thoracic duct would result in accumulation of huge amounts of fluid in the pleural (1).

Chylothorax can be traumatic or non-traumatic. 20\% of the traumatic cases are non-iatrogenic and can be caused by a fracture or dislocation, childbirth, forceful vomiting and penetrating trauma from knife or gun-shot injury. Oesophageal surgery, transhiatal approach predominantly, has an incidence of $4 \%$ only (2), when thoracic surgery has more involvement in causing chylothorax. Subclavian vein catheterisation radiation therapy and neck surgery are other iatrogenic causes.

Malignancy (most commonly is lymphoma at a $70 \%$ incidence rate), sarcoidosis, retrosternal goitre, amyloidosis, superior vena cava thrombosis, benign tumours, congenital duct abnormalities and diseases of the lymph vessels (yellow nail syndrome, lymphangioleiomyomatosis, haemangiomatosis) and idiopathic are the non-traumatic causes of chylothorax (1).

The clinical features of chylothorax depend on the rate of chyle loss. Some of the features are known to be: cough, dyspnoea, and chest pain. Effusion is predominantly on the right $(50 \%)$ and even bilateral. Damage to the duct above the fifth thoracic vertebra results in a left sided effusion, whereas damage to the duct below this level leads to a right sided effusion (3). The mortality rate has improved, mainly due to the more aggressive management plans implemented. Malignant and bilateral chylothoraces have the worst prognosis (4).
Treatment starts with a diagnostic thoracocentesis, which checks for chylomicrons and triglycerides. If the fluid is transudate and free of chylomicrons, then cardiac or liver disease might be responsible and a conservative treatment method is advised. If it is exudate, it might be due to radiotherapy or malignancy and again a conservative treatment, which consists of a total parenteral nutrition, intercostal drain insertion, talc pleurodesis and the administration of a somatostatin/octreotide. If the output of the drain is more than 1.5 liters per day or more than 1 liter for 5 days or there is a persistent leak for more than 2 weeks, or if the nutritional and metabolic compromise is present then surgical treatment is advised, with ligation of the leak under direct visualisation [videoassisted thoracoscopic surgery (VATS)/open intervention], surgical pleurodesis (malignant chylothorax), pleurectomy (historical) or pleuroperitoneal shunt. Surgical treatment is the predominant treatment method for chylothorax post oesophagectomy as well (5). Chylothorax postoesophagectomy, when treated surgically, has been shown to have mortality of $10 \%$ when in comparison to $50 \%$ mortality rate with other conservative measures (6). Fibrin glue or fibrin sealant, used to achieve haemostasis and to seal tissues, has been shown to be effective method in improving postoperative results for chylothorax following various thoracic procedures. Percutaneous image guided interventions (thoracic duct embolization and thoracic duct disruption) are increasingly being used to manage patients with a failed conservative therapy, high output chylothorax, and those who cannot tolerate surgical procedures (7). 
Several teams tried the thoracoscopic approach for the ligation of thoracic duct, or even percutaneous thoracic duct embolization $(8,9)$.

VATS can be used for both thoracic duct ligation and pleurodesis in chylothorax cases. It has been proven to be safer and more cost effective in treating chylothorax in comparison to open thoracotomy. It is performed under a single lung ventilation, and 3 ports technique, with positioning depending on the location of the leak. In right-sided cases, the first port is purposed for a $30^{\circ}$ scope and is inserted in the right 6 intercostal space. The second port is placed in the right posterior 8 intercostal space for dissection, and the third port is positioned in the anterior superior axillary line for lung retraction and instrumentation. If the thoracic duct is not visualized after pleural resection, mass ligation of the space in the posterior mediastinum once the aorta, azygos vein, and oesophagus have been identified, has proven useful in managing the problem. Visualization of the thoracic duct during VATS or an open thoracotomy can be enhanced by a preoperative ingestion of cream or milk, or injection of $1 \%$ Evans Blue dye. Repair using Open Thoracotomy is usually a last resort due to the high morbidity and mortality rates.

Recently, a team in China (Tang, et al.) came up with a novel technique. They anastomosed the thoracic duct to the azygos vein to treat recurrent chylothoraces post thoracic duct ligation (10). The hypothesis was that a repeated ligation of the thoracic duct will end up with increasing pressures, and a recurrent chylothorax. This gave the idea of draining the thoracic duct back into circulation through azygos vein. They state that the duct was unimpeded after 2 months. Also they feel that it is the better choices to anastomose the thoracic duct with the azygos vein at the level of the azygos vein bow, and it is stable and effective for the treatment of recurrent severe chylothoraces.

Although there is a need of open thoracotomy in order to treat chylothorax using this technique, there is a more physiological flow of the chyle and eventually treatment. It feels easily reproducible as well.

We believe a series of cases using this treatment, even for a first time chylothorax, would be useful to actually rate the effectiveness of the technique.

\section{Acknowledgements}

None.

\section{Footnote}

Conflicts of Interest: The authors have no conflicts of interest to declare.

\section{References}

1. McGrath EE, Blades Z, Anderson PB. Chylothorax: aetiology, diagnosis and therapeutic options. Respir Med 2010;104:1-8.

2. McWilliams A, Gabbay E. Chylothorax occurring 23 years postirradiation: literature review and management strategies. Respirology 2000;5:301-3.

3. Bessone LN, Ferguson TB, Burford TH. Chylothorax. Ann Thorac Surg 1971;12:527-50.

4. Milsom JW, Kron IL, Rheuban KS, et al. Chylothorax: an assessment of current surgical management. J Thorac Cardiovasc Surg 1985;89:221-7.

5. Dhakal P, Bastakoti S, Rayamajhi S. Chylothorax: a review of management options. Clinical Pulmonary Medicine 2017;24:66-8.

6. Bolger C, Walsh TN, Tanner WA, et al. Chylothorax after oesophagectomy. Br J Surg 1991;78:587-8.

7. Lyon S, Mott N, Koukounaras J, et al. Role of interventional radiology in the management of chylothorax: a review of the current management of high output chylothorax. Cardiovasc Intervent Radiol 2013;36:599-607.

8. Achildi O, Smith BP, Grewal H. Thoracoscopic ligation of the thoracic duct in a child with spontaneous chylothorax. J Laparoendosc Adv Surg Tech A 2006;16:546-9.

9. Binkert CA, Yucel EK, Davison BD, et al. Percutaneous treatment of high-output chylothorax with embolization or needle disruption technique. J Vasc Interv Radiol 2005;16:1257-62.

10. Tang H, Bai $Y$, Shen W, et al. Anastomosis of the thoracic duct and the azygos vein for the treatment of recurrent chylothoraxes. Eur J Cardiothorac Surg 2018;53:1093-4.

(English Language Editor: Jeremy Dean Chapnick, AME Publishing Company)

Cite this article as: Papoulidis P, Vidanapathirana P, Dunning J. Chylothorax, new insights in treatment. J Thorac Dis 2018;10(Suppl 33):S3976-S3977. doi: 10.21037/jtd.2018.09.94 